\title{
Characterization and Biomimetic Study of a Hydroxo-Bridged Dinuclear Phenanthroline Cupric Complex Encapsulated in Mesoporous Silica: Models for Catechol Oxidase
}

\author{
Chia-Hung Lee, ${ }^{\dagger}$ She-Tin Wong, ${ }^{\dagger}$ Tien-Sung Lin, ${ }^{*,+}$ and Chung-Yuan Mou ${ }^{*, \dagger}$ \\ Department of Chemistry, National Taiwan University, Taipei, Taiwan 106, and Department of Chemistry, \\ Washington University, St. Louis, Missouri 63130
}

Received: August 31, 2004; In Final Form: October 21, 2004

\begin{abstract}
We report the synthesis and characterization of a hydroxo-bridged dinuclear phenanthroline cupric complex, $\left[(\text { phen })_{2} \mathrm{Cu}-\mathrm{OH}-\mathrm{Cu}(\text { phen })_{2}\right]\left(\mathrm{ClO}_{4}\right)_{3}$ (HPC, phen $=$ phenanthroline $)$, dispersed in molecular sieves: MCM41's and sodium zeolite Y. We employed spectroscopic techniques (FT-IR, UV-visible, EPR, and EXAFS) to characterize and study the catalytic activities of immobilized HPC in the oxidation of 3,5-di-tert-butylcatechol (DTBC) to the corresponding quinone (3,5-di-tert-butylquinone, DTBQ) to mimic the functionality of catechol oxidases. HPC complexes can adsorb only on the outside surface of the Y zeolite due to its smaller pore size. The EXAFS spectrum gives $3.51 \AA$ for the $\mathrm{Cu} \cdots \mathrm{Cu}$ distance in HPC encapsulated in the nanochannels of $\mathrm{Al}-\mathrm{MCM}-41$ mesoporous solids, which is comparable to the $\mathrm{O} \cdots \mathrm{O}$ distance of the two hydroxyl groups of DTBC, and this made a simultaneous coordination of the diol group to the dicupric center possible. The resultant complex then allows the transfer of two electrons from DTBC to the dicupric center leading to the production of DTBQ. The nanochannels of calcined Al-MCM-41 mesoporous solids provide stability, due to confined space and surface charge, which could prevent excessive separation of the dinuclear cupric centers after removal of the hydroxo bridge in the catalytic process. A catalytic reaction scheme is proposed based on the spectroscopic data obtained in the characterization. The study demonstrates that HPC encapsulated in the nanochannels of $\mathrm{Al}-\mathrm{MCM}-41$ mesoporous materials could be a viable system for a broad range of catalytic oxidation to mimic natural occurring enzymes.
\end{abstract}

\section{Introduction}

Copper-containing proteins have taken part in many enzymatic activities, such as dioxygen transport and activation, electron transfer, reduction of nitrogen oxides, and hydrolytic chemistry. ${ }^{1}$ It was reported that type III copper proteins contain two copper centers that behave cooperatively. For instance, hemocyanins (Hcs) have been identified as the oxygentransporting protein of mollusks and arthropods, ${ }^{2,3}$ and catechol oxidases (COs) show catalytic oxidation of $o$-diphenols to $o$-quinones in the presence of oxygen. ${ }^{4}$ Recently, the crystal structures of the oxidized and the reduced form of COs from sweet potatoes were determined, where the oxidized COs contain the dinuclear met form, $\left[\mathrm{Cu}^{\mathrm{II}}-\mathrm{OH}^{-}-\mathrm{Cu}^{\mathrm{II}}\right]$, and each copper center is coordinated by three histidine nitrogen atoms. The $\mathrm{Cu}$ (II) centers contain a hydroxide bridge completing the fourcoordinated trigonal pyramidal coordination sphere with a $\mathrm{Cu} \cdot \cdots \mathrm{Cu}$ distance of $2.9 \AA{ }^{5,6}$ Another class of dicopper enzyme is tyrosinase (Tyr) from vertebrates and fungi which catalyzes the initial step in the formation of the pigment melanin from tyrosine. Tyr exhibits a broader substrate range; e.g., it can oxidize not only monophenols (such as tyrosine) to $o$-diphenols, but also $o$-diphenols (such as DOPA) to $o$-quinones. ${ }^{7}$

There have been several biomimetic studies of type III copper proteins using multidentate ligands, ${ }^{8}$ such as the H-BPMP type [2,6-bis[\{ bis(2-pyridylmethyl)amino $\}$ methyl]-4-methylphenol], ${ }^{9-13}$ the Hbbp type [1,3-bis(2-benzimidazolyl)-2-propanol], ${ }^{14-17}$ or macrocyclic Schiff base ligands, ${ }^{18,19}$ as model

* Corresponding authors. T.-S.L: fax, (314) 935-4481; e-mail, lin@ wustl.edu. C.-Y.M: fax, +886-2-23660954; e-mail, cymou@ntu.edu.tw.

National Taiwan University.

$\doteqdot$ Washington University. compounds. These studies have yielded better understanding of the structural functionality and reactivity relationship. The prerequisites of a catalytic biomimetics of the dicopper center are cage binding and a bridging ligand that holds two copper centers together. This is because the bridging ligand is usually removed in the deoxy state during the catalytic cycle. In enzymes, the peripheral binding is provided by histidine residues on the protein skeleton. In model compounds, this is often provided by a dinucleating macrocyclic ligand holding the dicopper center together. For instance, in the H-BPMP type, the ligand coordinated dinuclear cupric center contains both a hydroxo bridge and a phenoxy bridging ligand, where the phenoxy bridge holds the dinuclear cupric center in place while the hydroxo bridge is reversibly removed during the catalytic action. Another example is the Hbbp complex containing a dinuclear $\mathrm{Cu}$ (II) center in which each copper atom is coordinated by two benzimidazole nitrogen atoms and two bridging alkoxo oxygen atoms. Thus, these model compounds all contain at least two bridging ligands: one for electronic coupling and the other for structural cohesion.

However, a model compound of the met state of dinuclear copper complex containing only a single hydroxo bridge would be desirable for mimicking the structure and to gain a better understanding of the catalytic nature of COs. In this singlebridge complex, catechol will have less steric hindrance to approach the dinuclear active site during the oxidation reaction. A steric match between the two hydroxyl oxygen atoms of catechol and the dinuclear copper center would facilitate the electron transfer between them. We therefore proceed to synthesize a hydroxo-bridged dinuclear phenanthroline cupric complex, $\left[(\text { phen })_{2} \mathrm{Cu}-\mathrm{OH}-\mathrm{Cu}(\text { phen })_{2}\right]\left(\mathrm{ClO}_{4}\right)_{3}(\mathrm{HPC}$, phen $=$ 
phenanthroline). For the monobridged HPC to function as a biomimetic catalyst, some support is needed to hold the deoxy state together. It has been reported that immobilizing catalytic centers in a solid support can closely mimic the natural occurring enzymes, where the solid support could provide both the proper geometry and distance for catalytic centers, and enhance the stability of metal centers. ${ }^{19-24}$ Therefore, we turn our attention to investigating the HPC complex supported on solid porous materials.

In the past few years, we have studied extensively the syntheses, characterizations, and applications of mesoporous MCM-41 materials. ${ }^{25-27}$ We found that MCM-41 materials with large pore diameters $(2-5 \mathrm{~nm})$ and accessible surface modification with functional groups and ionic species are good candidates for encapsulating catalytic centers which would also allow us to perform biomimetic studies of these systems. We recently reported a one-step self-assembly synthesis of dinuclear cupric complexes by mixing $\mathrm{CuCl}_{2}-$ phenanthroline solution in the presence of mesoporous MCM-41 materials. ${ }^{28}$ There we studied the oxidation of benzyl alcohol by tert-butylhydroperoxide as an oxidant; the dinuclear copper catalysts showed better catalytic stability than the mononuclear cupric complexes. The results were explained in terms of the formation of active oxygen species in the reaction involving the bridging ligand to retain the integrity of the cupric centers. The encapsulations in mesoporous silica further make the catalysts easier to handle especially during separation from the liquid medium. Furthermore, the confined space of the support should also play an important role in stabilizing and/or modifying the catalytic performance by influencing the chemoselectivity, regioselectivity, and shape selectivity of the reaction.

The mesoporous surface of MCM-41 may be envisioned as an equivalent to the backbone of the protein skeleton of natural biological systems where the two copper nuclei are held stably to the surface in carrying out the presumed enzymatic functions. In this report, we test HPC complexes dispersed in mesoporous silica to study their catalytic efficacy and functionalities in comparison with native COs. Specifically, we investigated the abilities of our model systems in the catalytic oxidation of $o$-diphenol to $o$-quinone by employing 3,5-di-tert-butylcatechol (DTBC) to test the catecholase activity of dicupric complexes. ${ }^{9-19,29}$ By spectroscopic characterization, we shall show that HPC complexes are stably immobilized inside the mesoporous channels of $\mathrm{Al}-\mathrm{MCM}-41$, but not in Y zeolite. We shall further show that the model reaction has relatively high chemical activity and selectivity of DTBC oxidation. Thus, we shall demonstrate the mesoporous $\mathrm{Al}-\mathrm{MCM}-41$ channels indeed provide the stability, due to confined space and surface charge, that could prevent excessive separation of the dinuclear cupric centers after removal of the hydroxo bridge in the catalytic process.

\section{Experimental Section}

1. Preparation of Compounds. (a) Synthesis of $\left[(\text { phen })_{2} \mathrm{Cu}-\right.$ $\mathrm{OH}-\mathrm{Cu}(\text { phen })_{2} \mathrm{~J}\left(\mathrm{ClO}_{4}\right)_{3}$ Complex. The sample was prepared according to the method of Haddad et al. ${ }^{30}$ Briefly, $0.5 \mathrm{~g}$ of $\mathrm{CuSO}_{4} \cdot 5 \mathrm{H}_{2} \mathrm{O}$ in $40 \mathrm{~mL}$ of EtOH and $60 \mathrm{~mL}$ of $\mathrm{H}_{2} \mathrm{O}$ was added to $0.74 \mathrm{~g}$ of 1,10 -phenanthroline under continuous stirring. When the solution gradually turned an intense blue color, a fine precipitate was formed. Then $0.06 \mathrm{~g}$ of $\mathrm{KOH}$ was added to this mixture, and the solution was then filtered. To the filtrate was added $2.0 \mathrm{~g}$ of $\mathrm{NaClO}_{4}$ in $5 \mathrm{~mL}$ of $\mathrm{H}_{2} \mathrm{O}$. Almost instantaneously a blue-green product precipitated. The product was recrystallized from $300 \mathrm{~mL}$ of $90{ }^{\circ} \mathrm{C}$ hot water. (b) Synthesis of Particulate Al-MCM-41. To anchor the positively charged copper centers to the surface of MCM-41 channels, we modified the framework with Al to generate a negatively charged surface. The synthetic method of Al-MCM41 was reported previously. ${ }^{31}$ Briefly, sodium silicate and sodium aluminate were added to a clear aqueous solution of the surfactant under stirring and a gel mixture was formed. After stirring for about $10 \mathrm{~min}$ at room temperature, the proper amount of $1.2 \mathrm{M}$ sulfuric acid was added to the gel mixture with a pipet. The $\mathrm{pH}$ value of the final mixture was adjusted to about 10 . Generally, the molar composition of the resultant gel of $\mathrm{Al}-$ MCM-41 materials is 0.47 surfactant, $59.8 \mathrm{H}_{2} \mathrm{O}, 0.03 \mathrm{NaAlO}_{2}$, $1 \mathrm{SiO}_{2}, 0.78 \mathrm{NaOH}$, and $0.32 \mathrm{H}_{2} \mathrm{SO}_{4}$. The resultant gel mixture was hydrothermally reacted at $100{ }^{\circ} \mathrm{C}$ for $48 \mathrm{~h}$ in a static autoclave. The as-synthesized product was recovered by filtration and washed thoroughly with deionized water. The dried product was then calcined at $560{ }^{\circ} \mathrm{C}$ in air for $6 \mathrm{~h}$ to remove the template.

(c) Synthesis of Tubular Al-MCM-41. To compare the catalytic activity of HPC complex in different morphologies of MCM-41, we prepared a new family of M41S with tubular morphology via a special delayed-neutralization process. The walls of the micrometer-sized tubules consist of coaxial cylindrical pores, nanometers in size, that are characteristic of MCM-41. There are defects in the structure, which improve the interchannel diffusion or porosity of the catalyst. However, tubular MCM-41 can only be synthesized in a narrow range of water content, of temperature, or upon addition of 1-alkanols. The detailed synthetic procedures and components are given elsewhere. ${ }^{26}$

(d) Methods To Prepare Supported HPC Complexes. The methods to encapsulate HPC in the nanochannels of Al-MCM41 solids differ from the one-step self-assembly method reported previously. ${ }^{28}$ Specifically, we prepared HPC and Al-MCM41 separately to gain a better quality control. We applied the following two methods to prepare various supported HPC complexes:

(i) The first was the ion-exchange method. An exchange solution containing HPC was first prepared. Normally, $100 \mathrm{~mL}$ of $\mathrm{H}_{2} \mathrm{O}-\mathrm{EtOH}$ (40:60) solution contained $0.2 \mathrm{~g}$ of HPC. About $0.4 \mathrm{~g}$ of the sodium form of aluminum-substituted MCM-41 $(\mathrm{Si} / \mathrm{Al} \approx 33)$ or NaY zeolite was then added to the exchange solution and stirred at $30{ }^{\circ} \mathrm{C}$ for nearly $1.5 \mathrm{~h}$. The solid was then separated by filtration, washed with $100 \mathrm{~mL}$ of $\mathrm{EtOH}$, and dried under vacuum before storage. The final products are denoted hereafter as $\mathrm{HPC}-\mathrm{M}_{\mathrm{P}}, \mathrm{HPC}-\mathrm{M}_{\mathrm{T}}, \mathrm{HPC}-\mathrm{Y}$, where the particulate and tubular MCM-41 are denoted by the subscripts $\mathrm{P}$ and T, respectively. Sodium Y zeolite is denoted as Y.

(ii) The second method was the impregnation method. The preparation procedure for this method is similar to the ionexchange method except that pure silica MCM-41 was used. The final product is denoted hereafter as HPC/MPS.

(e) Catalytic Activities of $H P C-M_{P}, H P C-M_{T}$, and $H P C-Y$ Samples. The catalytic activities were evaluated at $25^{\circ} \mathrm{C}$ by a reaction with 3,5-di-tert-butylcatechol (DTBC) under aerobic conditions to mimic catecholase activities. A typical catalytic condition is the following: $0.05 \mathrm{~g}$ of catalyst was first placed in a $50 \mathrm{~mL}$ round-bottom flask with a condenser cooled at $5^{\circ} \mathrm{C}$, and then $0.05 \mathrm{M} \mathrm{DTBC}$ in $10 \mathrm{~mL}$ of methanol solution was added. After stirring for $5 \mathrm{~min}$, three different amounts of triethylamine were added: 0,15 , and $30 \mu \mathrm{L}$. Aliquots were withdrawn during the reaction course; they were diluted 10 times with methanol and analyzed by a Gilson 306 liquid chromatograph using an RP-18 $(4.6 \times 250 \mathrm{~mm})$ column. The mobile 
phase was an acetonitrile/water mixed solution $\left(\mathrm{CH}_{3} \mathrm{CN}: \mathrm{H}_{2} \mathrm{O}\right.$ $=60: 40$ ) with a flow rate of $1 \mathrm{~mL} / \mathrm{min}$, and a UV-vis detector was set at $260 \mathrm{~nm}$ wavelength. The retention times of DTBQ and DTBC under these conditions were 13.1 and $14.5 \mathrm{~min}$, respectively. For the quantitative assay of DTBC and DTBQ, the HPLC chromatogram was calibrated using known quantities of DTBC and DTBQ (Acros). The TON (turnover number) was determined by the moles of DTBC converted per mole of copper in the catalyst.

2. Characterization Techniques. Nitrogen and carbon contents of the sample were analyzed with a Perkin-Elmer CHN2400 instrument. Copper contents of the sample were analyzed with a simultaneous ICP-AES allied analytical system (JarrelAsh, Model ICAP 9000). FT-IR spectra were recorded on a Nicolet 550 spectrometer using a $\mathrm{KBr}$ pellet. About $1 \mathrm{mg}$ of sample was mixed with $300 \mathrm{mg}$ of dried $\mathrm{KBr}$ and then pressed. UV-visible spectra were taken on a Hitachi U-3010 spectrophotometer. When dealing with solid samples, an integrating sphere was included to collect the reflected light.

A Bruker EMX EPR spectrometer (X-band) was employed to measure the electron paramagnetic resonance (EPR) spectra of the samples. The powdered sample used for the analysis was introduced in a quartz tubing of $4 \mathrm{~mm}$ outside diameter. The sample was degassed and sealed under vacuum. The spectrometer was equipped with a variable temperature controller, which allowed us to record spectra at low temperatures (above the boiling temperature of liquid nitrogen). Typical spectrometer settings were microwave frequency $9.4 \mathrm{GHz}$, microwave power $20 \mathrm{~mW}$, modulation amplitude $2-20 \mathrm{G}$, and one scan at $167 \mathrm{~s}$.

The studies of extended X-ray absorption fine structure (EXAFS) were performed at the Synchrotron Radiation Research Center in Hsinchu, Taiwan. The storage ring was operated at about $1.5 \mathrm{GeV}$ with a ring current of about $200 \mathrm{~mA}$. These experiments were done at room temperature in the transmission mode with ionization detectors. Each energy scan took about $25 \mathrm{~min}$. An additional scan may also be recorded immediately after the first scan to check the difference. A copper metal foil was placed behind the sample as an on-line energy reference in each scan. The resulting EXAFS data were analyzed using the standard FEFF6 program. The data were $k^{3}$-weighted to compensate for the attenuation of EXAFS amplitude at high $k$ and then Fourier transformed over the $k$-range of 2.45-13.5 $\mathrm{A}^{-1}$ with a Hanning apodization function of $d k=2 \mathrm{~A}^{-1}$. Curve fitting of experimental data was done with copper metal as the reference as reported in the study of Brown et al. ${ }^{32}$

\section{Results and Discussion}

1. Chemical Analysis. The X-ray structure of HPC was determined by Haddad et al. ${ }^{30}$ The coordination geometry about each copper ion is approximately trigonal bipyramidal with the bridging hydroxide ion occupying an equatorial site. According to the elemental analyses, each copper ion is coordinated to two phen ligands on the average. The amounts of phen ligand and copper ion in the mesoporous samples prepared by different methods are given in Table 1. From the table, we note that $\mathrm{HPC}-\mathrm{M}_{\mathrm{P}}$ and $\mathrm{HPC}-\mathrm{M}_{\mathrm{T}}$ have a similar amount of copper content, $8.14 \mathrm{vs} 7.22 \mathrm{mmol}$ of $\mathrm{Cu}$, respectively, per $100 \mathrm{~g}$ of samples. The coordination number of each phen ligand to copper ion is 2.5 and 2.3 , respectively. These coordination numbers are slightly greater than that of the pure HPC complex (phen/ $\mathrm{Cu}=2.0$ ). Therefore, we are certain the $\mathrm{HCP}-\mathrm{M}_{\mathrm{P}}$ and $\mathrm{HPC}-$ $\mathrm{M}_{\mathrm{T}}$ samples contain a large amount of dinuclear copper complexes. The results also agree with the analysis of the EPR and UV-vis spectra of these samples (see below).
TABLE 1: Compositions of Supported HPC: Contents and Mole Ratios

\begin{tabular}{cccc}
\hline sample & $\begin{array}{c}\text { mmol of phen }{ }^{a} / \\
100 \mathrm{~g} \text { of sample }\end{array}$ & $\begin{array}{c}\text { mmol of Cu/ } \\
100 \mathrm{~g} \text { of sample }\end{array}$ & $\begin{array}{c}\text { phen/ } \\
\mathrm{Cu} \text { mole ratio }\end{array}$ \\
\hline HPC- $-\mathrm{M}_{\mathrm{P}}$ & 20.35 & 8.14 & 2.5 \\
$\mathrm{HPC}-\mathrm{M}_{\mathrm{T}}$ & 16.61 & 7.22 & 2.3 \\
$\mathrm{HPC}-\mathrm{M}_{\mathrm{T}}{ }^{b}$ & 22.57 & 6.84 & 3.3 \\
$\mathrm{HPC}-\mathrm{M}_{\mathrm{T}}{ }^{c}$ & $d$ & 6.70 & $d$ \\
$\mathrm{HPC} / \mathrm{M}_{\mathrm{PS}}$ & 6.21 & 1.94 & 3.2 \\
HPC$-\mathrm{Y}$ & 20.78 & 13.85 & 1.5
\end{tabular}

${ }^{a}$ Calculated from the nitrogen content of the solids. ${ }^{b}$ Elemental analysis of the solids after the catalytic reaction in the absence of triethylamine. ${ }^{c}$ Same as $b$ except $30 \mu \mathrm{L}$ of triethylamine was added in the catalytic process. ${ }^{d}$ No data given.

To verify that HPC complex can stably exist in Al-MCM41 channels (pore diameter $=2.8 \mathrm{~nm}$ ), we measured the elemental analysis of the HPC- $\mathrm{M}_{\mathrm{T}}$ samples after the catalytic reaction which still contained a large quantity of copper ions (6.84 mmol of $\mathrm{Cu} / 100 \mathrm{~g}$ of samples). In a severe reaction condition where $30 \mu \mathrm{L}$ of triethylamine was added in the catalytic process, we still found $6.70 \mathrm{mmol}$ of $\mathrm{Cu} / 100 \mathrm{~g}$ of samples, which indicated only $7 \%$ of copper was leached out. On the other hand, the impregnation samples $\left(\mathrm{HPC} / \mathrm{M}_{\mathrm{PS}}\right)$ were found to contain less phen ligand $(6.21 \mathrm{mmol}$ of phen/100 $\mathrm{g}$ of samples) and copper ion (1.94 mmol of $\mathrm{Cu} / 100 \mathrm{~g}$ of samples), which corresponded to a low loading of HPC complexes. The low loading of HPC complexes inside the channels may arise from the lack of the electrostatic interaction. Furthermore, the microporous $\mathrm{Y}$ zeolites have smaller channels $(0.74 \mathrm{~nm})$ than the molecular size of HPC $(\sim 0.8 \mathrm{~nm})$; thus they can only be adsorbed on the external surface of $\mathrm{Y}$ zeolites. The greater amount of copper ion (13.85 mmol of $\mathrm{Cu} / 100 \mathrm{~g}$ of samples) may come from the exchange of more $\mathrm{Cu}(\mathrm{II})$ ions on the framework or more mononuclear cupric complexes migrated into the channels of Y zeolites.

2. Thermogravimetric Analysis (TGA). The TGA profiles of the samples prepared from ion exchange are shown in Figure 1. The TG curves (solid line) show that the total weight loss is associated with the HPC complex upon the decomposition of organic ligands. The decomposition of the heating process mainly comes from the combustion of phen ligands and loss of $\mathrm{H}_{2} \mathrm{O}$ from bridge $\mathrm{OH}^{-}$groups of HPC complexes, which gives copper oxide as the final decomposition product. The dashed lines refer to the differential TG (DTG) curves. These curves indicate that the decomposition temperatures are $592{ }^{\circ} \mathrm{C}$ for $\mathrm{HPC}-\mathrm{M}_{\mathrm{P}}$ (Figure 1a) and $593{ }^{\circ} \mathrm{C}$ for $\mathrm{HPC}-\mathrm{M}_{\mathrm{T}}$ (Figure 1b) samples. Samples of HPC-Y (Figure 1c) have a lower decomposition temperature at $528{ }^{\circ} \mathrm{C}$. We may conclude that $\mathrm{Al}-\mathrm{MCM}-41$ provides a stable environment to prevent the decomposition of the complex at higher temperatures. This is further verified in the thermal behavior of HPC-Y complexes, where the pore size of the Y zeolite is smaller than that of the HPC complex; therefore the HPC complexes are merely dispersed on the unprotected external surface of the silicate, and $\mathrm{HPC}-\mathrm{Y}$ samples have worse heat stability than $\mathrm{HPC}-\mathrm{M}_{\mathrm{P}}$ and $\mathrm{HPC}-\mathrm{M}_{\mathrm{T}}$. To further demonstrate that the channels of $\mathrm{Al}-$ MCM-41 can provide stability for the dinuclear cupric complexes, HPC complexes were supported on the uncalcined samples of $M_{P}$ and $M_{T}$, where the channels are mostly occupied by surfactants. Thus, the HPC complexes are most likely located only on the external surface of the uncalcined samples. Their TGA and DTG showed low decomposition temperature at 525 and $519^{\circ} \mathrm{C}$, respectively, as shown in Figure 1d and Figure 1e. The weight loss at $300{ }^{\circ} \mathrm{C}$ mainly arises from the combustion of surfactants. 


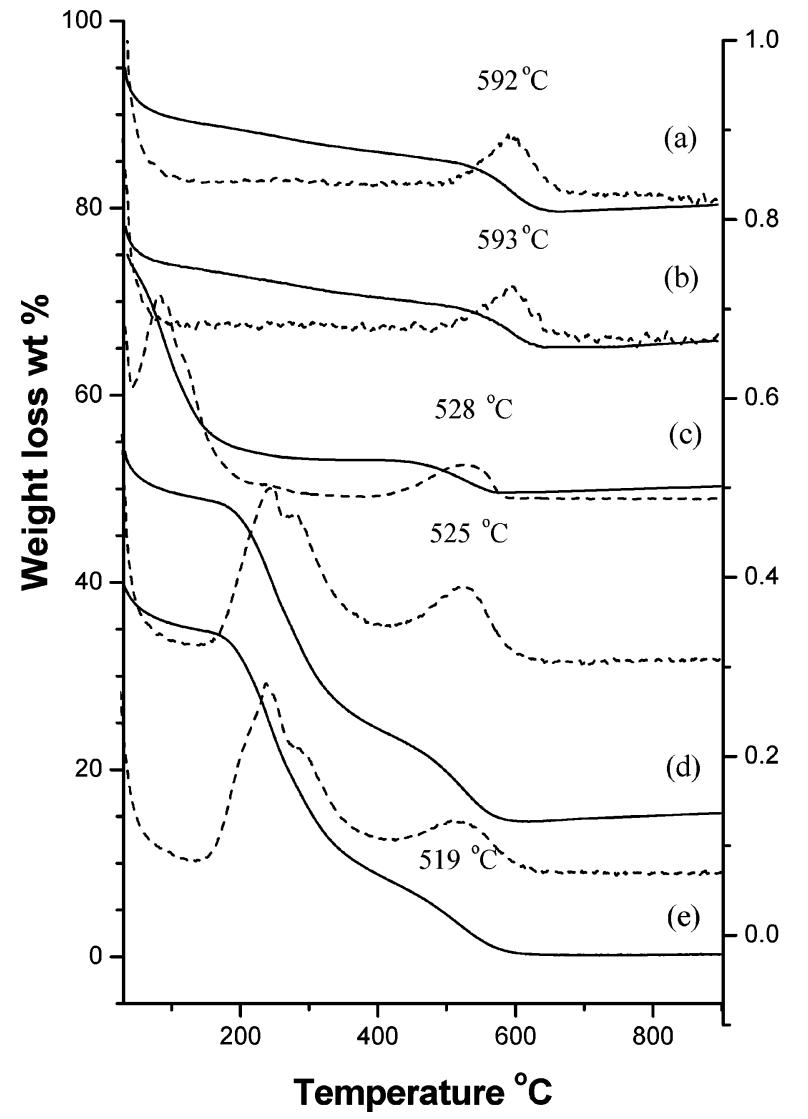

Figure 1. TGA/DTG profiles of (a) $H P C-M_{P}$, (b) $H P C-M_{T}$, (c) HPC-Y, (d) HPC-uncalcined- $\mathrm{M}_{\mathrm{P}}$, and (e) HPC-uncalcined- $\mathrm{M}_{\mathrm{T}}$ solids. Solid lines are for weight loss and dashed lines are for derivative weight loss.

3. Spectral Characterizations. (a) FT-IR Spectra. We applied IR spectroscopy to study the backbone structure of both the $\mathrm{SiO}_{2}$ network and the organic side groups present within and on the surface of these materials. The IR spectra of the samples used in the experiments are displayed in Figure 2. The spectrum of pure HPC crystalline solids shows a peak at 3511 $\mathrm{cm}^{-1}$ with medium intensity which is assigned to the $v(\mathrm{O}-\mathrm{H})$ band attributed to the bridging $\mathrm{OH}^{-}$group. The bands at 3071 and $1431 \mathrm{~cm}^{-1}$ were attributed to the $\mathrm{C}-\mathrm{H}$ stretching mode of the phen ring. ${ }^{33}$ Other peaks at 1588 and $1519 \mathrm{~cm}^{-1}$ are associated with the phen ligand and are consistent with coordination of the nitrogen atoms to the metal..$^{34}$ The peak at $1093 \mathrm{~cm}^{-1}$ is assigned to $\mathrm{ClO}_{4}{ }^{-}$vibration. The unsplit nature of this band may indicate that $\mathrm{ClO}_{4}{ }^{-}$is just a counterion and not involved in coordination. ${ }^{35}$

After ion exchange of HPC complex into the sodium form of $\mathrm{Al}-\mathrm{MCM}-41$ and $\mathrm{Y}$ zeolite, we observed a broad band $\left(3000-3500 \mathrm{~cm}^{-1}\right)$ arising from the $\mathrm{O}-\mathrm{H}$ stretch of the absorbed molecular $\mathrm{H}_{2} \mathrm{O}$. The vibration of the HPC bridging $\mathrm{OH}^{-}$group may be buried beneath. The bands at $1077 \mathrm{~cm}^{-1}$ (with a shoulder at $1236 \mathrm{~cm}^{-1}$ ) and $790 \mathrm{~cm}^{-1}$ are assigned to $\mathrm{Si}-\mathrm{O}-\mathrm{Si}$ vibration. The band at $1639 \mathrm{~cm}^{-1}$ is presumably caused by $\mathrm{H}_{2} \mathrm{O}$ deformation. The bands observed at 1525 and $1429 \mathrm{~cm}^{-1}$ may arise from phen ligands. These spectral features also support the fact that HPC complex is indeed encapsulated in the channels. We also exchange the uncalcined Al-MCM41 samples with HPC solution. There is still a large amount of the surfactant present in the sample after the ion-exchange process. We observed bands at 2860 and $2931 \mathrm{~cm}^{-1}$ which should mainly come from the $v(\mathrm{C}-\mathrm{H})$ mode of the surfactant, and 1525 and $1429 \mathrm{~cm}^{-1}$ bands of phen ligands are

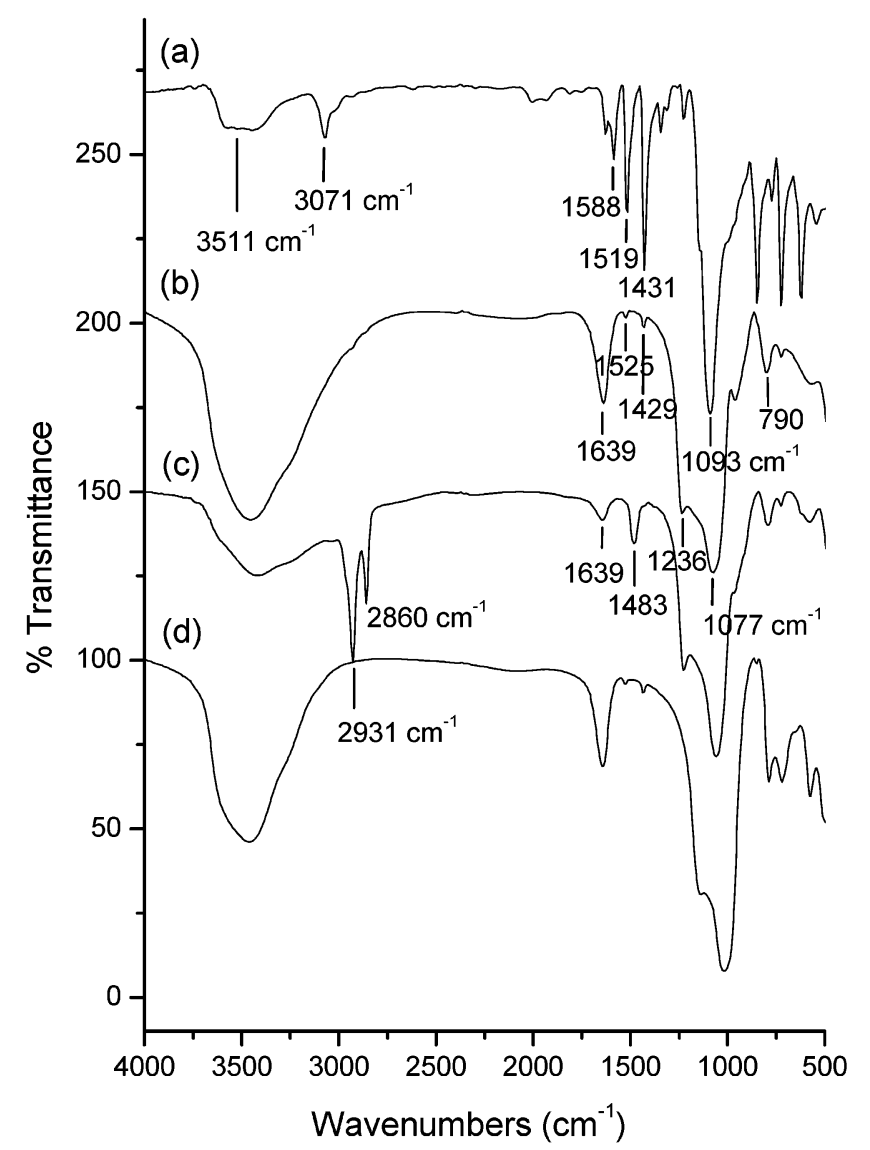

Figure 2. IR spectra of (a) $\mathrm{HPC}$ crystalline solids, (b) $\mathrm{HPC}-\mathrm{M}_{\mathrm{P}}$, (c) HPC-uncalcined- $\mathrm{M}_{\mathrm{P}}$, and (d) HPC $-\mathrm{Y}$ solids.

reduced to being almost invisible. These results indicate that uncalcined Al-MCM-41 samples have lower loading of HPC because the channels have been occupied by the surfactant. HPC complex can only absorb on the small external surface $(\sim 50$ $\mathrm{m}^{2} / \mathrm{g}$ of support) of the silicate.

(b) UV-Visible Spectra. The solid state reflectance spectra of neat HPC solids ground with tubular forms of $\mathrm{Al}-\mathrm{MCM}$ $41, \mathrm{HPC}-\mathrm{M}_{\mathrm{T}}$, and $\mathrm{HPC}-\mathrm{M}_{\mathrm{P}}$ are shown in curves $\mathrm{a}, \mathrm{b}$, and $\mathrm{c}$, respectively, of Figure 3. These spectra display three peaks between 200 and $450 \mathrm{~nm}$. The peak at $220 \mathrm{~nm}$ is assigned to the $\pi-\pi$ transition band of phenanthroline, the peak at $270 \mathrm{~nm}$ is the characteristic charge-transfer band of ligand to metal, and the one at $350 \mathrm{~nm}$ corresponds to the charge-transfer band from the $\mathrm{OH}^{-} \rightarrow \mathrm{Cu}$ orbital which is absent in the mononuclear copper complexes. ${ }^{21,36-37}$ Another broad absorption band ranging from 600 to $800 \mathrm{~nm}$ is assigned to the $\mathrm{d}-\mathrm{d}$ transition band. ${ }^{12,13}$ We note that the samples of $\mathrm{HPC}-\mathrm{M}_{\mathrm{T}}$ and $\mathrm{HPC}-$ $\mathrm{M}_{\mathrm{P}}$ have a higher absorption peak at $350 \mathrm{~nm}$ than the HPC-Y sample (Figure 3d, nearly invisible). The disappearance of shoulder at $350 \mathrm{~nm}$ of HPC $-\mathrm{Y}$ sample should come from the low loading of HPC complexes due to the small cage size. On the other hand, the higher intensity of absorption at $350 \mathrm{~nm}$ of $\mathrm{HPC}-\mathrm{M}_{\mathrm{T}}$ and $\mathrm{HPC}-\mathrm{M}_{\mathrm{P}}$ samples indicates that the HPC complexes have high loading inside the nanochannels of $\mathrm{Al}-$ MCM-41. The results are consistent with the EPR studies (see below).

We further studied the UV-visible spectra of the catalytic oxidation of DTBC in the absence (Figure 3e) or presence (Figure 3f) of triethylamine. At the end of the catalytic reaction, the $\mathrm{HPC}-\mathrm{M}_{\mathrm{T}}$ solid was separated by filtration and then washed twice with methanol and dried under vacuum. The chargetransfer band of Figure 3e,f at $350 \mathrm{~nm}$ was still visible, so we 




Figure 3. Diffuse reflectance UV-visible spectra of (a) net HPC crystalline solids ground with tubular form of Al-MCM-41, (b) HPC$\mathrm{M}_{\mathrm{T}}$, (c) $\mathrm{HPC}-\mathrm{M}_{\mathrm{P}}$, (d) HPC $-\mathrm{Y}$, (e) $\mathrm{HPC}-\mathrm{M}_{\mathrm{T}}$ after reaction with DTBC for $20 \mathrm{~min}$, and (f) same as (e) except $30 \mu \mathrm{L}$ of triethylamine added in the catalytic process.

TABLE 2: Turnover Number (TON) and Selectivity of DTBQ for Oxidation of DTBC with Dioxygen and Various Catalysts

\begin{tabular}{cccc}
\hline catalyst & $\begin{array}{c}\text { base vol } \\
(\mu \mathrm{L})\end{array}$ & $\begin{array}{c}\mathrm{TON}^{a} \\
\left(\mathrm{~h}^{-1}\right)\end{array}$ & $\begin{array}{c}\text { selectivity of } \\
\mathrm{DTBQ}^{b}(\%)\end{array}$ \\
\hline HPC-M $-\mathrm{M}_{\mathrm{P}}$ & 0 & 22 & 75 \\
& 15 & 76 & 95 \\
HPC-M & 30 & 117 & 100 \\
& 0 & 35 & 68 \\
$\mathrm{HPC}-\mathrm{Y}$ & 15 & 112 & 77 \\
& 30 & 137 & 100 \\
& 0 & 15 & 43 \\
& 15 & 40 & 73 \\
& 30 & 57 & 69
\end{tabular}

${ }^{a} \mathrm{TON}=$ moles of substrate converted per mole of copper in catalyst. ${ }^{b}$ Selectivity of DTBQ $(\%)=\{[\mathrm{QP}] /([\mathrm{CA}]-[\mathrm{CU}])\} \times 100 .[\mathrm{CA}]$, amount of 3,5-di-tert-butylcatechol added; [CU], amount of 3,5-di-tertbutylcatechol unreacted; [QP], amount of 3,5-di-tert-butylquinone produced.

infer that the HPC complexes were stable in the nanochannels after the catalytic cycle. In the absence of triethylamine (Figure 3e), a new band appears at about $500 \mathrm{~nm}$ that may presumably be assigned to a catecholate $\rightarrow \mathrm{Cu}^{\mathrm{II}}$ charge-transfer band of met-D state intermediate (see Scheme 1). ${ }^{12}$ It is remarkable that the absorption at $500 \mathrm{~nm}$ disappeared upon the addition of $30 \mu \mathrm{L}$ of triethylamine in the catalytic process (Figure 3f), which also increased the rate of DTBC conversion with a 4-fold increase in TON (turnover number) (see below and Table 2). During $1 \mathrm{~h}$ of reaction time, all the intermediate state (met-D) returned to the met state and DTBQ was formed as the product.

(c) EPR Spectra. HPC complexes in met form, $\left[\mathrm{Cu}^{\mathrm{II}}-\mathrm{OH}^{-}-\right.$ $\mathrm{Cu}^{\mathrm{II}}$ ], contain two $\mathrm{Cu}$ (II) centers bridged by a hydroxide group. The two unpaired electrons will undergo electron-exchange coupling through the intervening hydroxide bridging group. When the $\mathrm{Cu} \cdots \mathrm{Cu}$ distance is long (weak superexchange), the EPR spectrum is analogous two independent doublet states. If the two $\mathrm{Cu}$ (II) ions are in a moderate interaction, the ground state of the dicupric center is a singlet and the triplet state can be thermally populated. Thus, we expect to observe the spectrum of half-field $\Delta M_{s}= \pm 2$ transition at ca. $1600 \mathrm{G}$ at moderate temperatures and a broad signal in the range from 2000 to 4400 $\mathrm{G}\left(\Delta M_{s}= \pm 1\right)$. For a doubly bridged structure with shorter

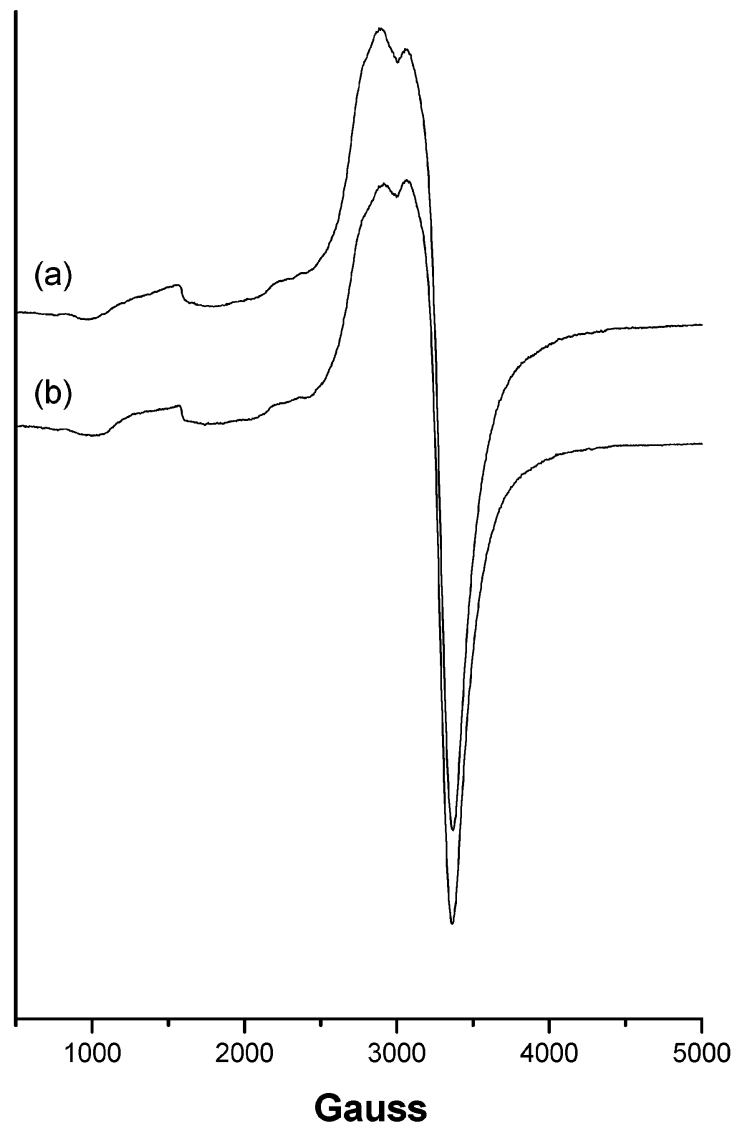

Figure 4. EPR spectra of the following samples at $80 \mathrm{~K}$ : (a) HPC$\mathrm{M}_{\mathrm{T}}$ and (b) HPC $-\mathrm{M}_{\mathrm{P}}$.

$\mathrm{Cu} \cdots \mathrm{Cu}$ distance, which will give rise a fast superexchange interaction, the EPR spectrum is silent. The strong interaction between two copper nuclei is an antiferromagnetic coupling. ${ }^{9-11,16,19}$

The EPR spectra of $\mathrm{HPC}-\mathrm{M}_{\mathrm{T}}$ and $\mathrm{HPC}-\mathrm{M}_{\mathrm{P}}$ samples at 80 $\mathrm{K}$ are shown in Figure 4a,b. Both spectra display a $\Delta M_{s}= \pm 2$ transition at $1600 \mathrm{G}$ and a broad $\Delta M_{s}= \pm 1$ signal from 2000 to $4000 \mathrm{G}$. The EPR features indicate that the interacting $\mathrm{Cu}(\mathrm{II})$ ions are in a moderate coupling. The signal in the $\Delta M_{s}= \pm 1$ region may also overlap with signal from a small amount of mononuclear cupric complexes. The mononuclear cupric complexes may come from either the Lewis acid (Al-MCM-41) catalytic activities in dissociating the bridge $\mathrm{OH}$ group in the ion-exchanging process, or partial dissociation of HPC in the ion-exchange solution media.

The EPR spectra of HPC-Y, HPC- uncalcined- $\mathrm{M}_{\mathrm{T}}$, and HPC-uncalcined-M $\mathrm{M}_{\mathrm{P}}$ samples are shown in curves $\mathrm{a}, \mathrm{b}$, and $\mathrm{c}$, respectively, of Figure 5. We note that the spectra displayed in Figure 5 are void of $\Delta M_{s}= \pm 2$ transition, a characteristic of moderately coupled dinuclear $\mathrm{Cu}$ (II) complexes. The signals at 2500-3600 G indicate the presence of a typical mononuclear $\mathrm{Cu}$ (II) center with characteristic four-line hyperfine patterns $\left(I=3 / 2\right.$ for both ${ }^{63} \mathrm{Cu}$ and $\left.{ }^{65} \mathrm{Cu}\right)$. The paramagnetic parameters are $g_{\|}=2.328, A_{\|}=157 \mathrm{G}$ for HPC $-\mathrm{Y}$, and $g_{\|}=2.277, A_{\|}=$ $171 \mathrm{G}$, and $g_{\|}=2.285, A_{\|}=170 \mathrm{G}$ for ion-exchanged HPC of uncalcined $\mathrm{M}_{\mathrm{T}}$ and $\mathrm{M}_{\mathrm{P}}$ samples, respectively. Previous $\mathrm{Cu}(\mathrm{II})$ EPR studies indicated that cupric ions with tetrahedral symmetry will have spin Hamiltonian parameters in the range of $g_{\|}=2.516$ and $A_{\|}=70 \mathrm{G}$, while with square planar symmetry the parameters are in the range of $g_{\|}=2.245$ and $A_{\|}=170 \mathrm{G}^{38,39}$ Cupric ions with distorted octahedral symmetry and square pyramidal symmetry are between these values. When nitrogen 
SCHEME 1: Catalytic Cycle for Oxidation of DTBC in the Presence of Dioxygen by Dinuclear Copper Complexes Encapsulated in the Nanochannels of MCM-41 Mesoporous Materials


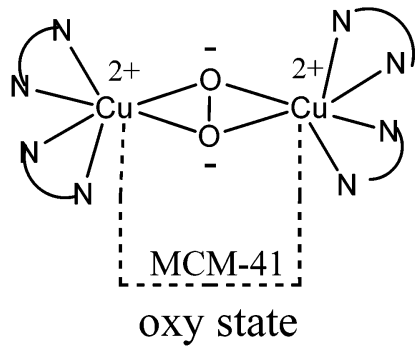

atoms coordinate to cupric ions with a given symmetry, the value will increase in $A_{\|}$and decrease in $g_{\|}$as compared to the cupric ions coordinated by oxygen atoms with the same symmetry. ${ }^{39}$ Our measured $g$ values and hyperfine coupling constants are similar to those for the $\mathrm{Cu}(\mathrm{II})$ ions in distorted octahedral symmetry.

The results in EPR spectra in Figures 4 and 5 are consistent with those of the chemical analysis and UV-visible spectra in that the $\mathrm{HPC}-\mathrm{M}_{\mathrm{P}}$ and $\mathrm{HPC}-\mathrm{M}_{\mathrm{T}}$ samples have high loading of dinuclear cupric complexes, but the $\mathrm{Y}$ zeolite can only ion exchange the mononuclear cupric complexes due to the small pore size.

Since HPC $-\mathrm{M}_{\mathrm{T}}$ systems exhibit unique dinuclear $\mathrm{Cu}$ (II) EPR spectra, we focused our attention on the changes of EPR spectra
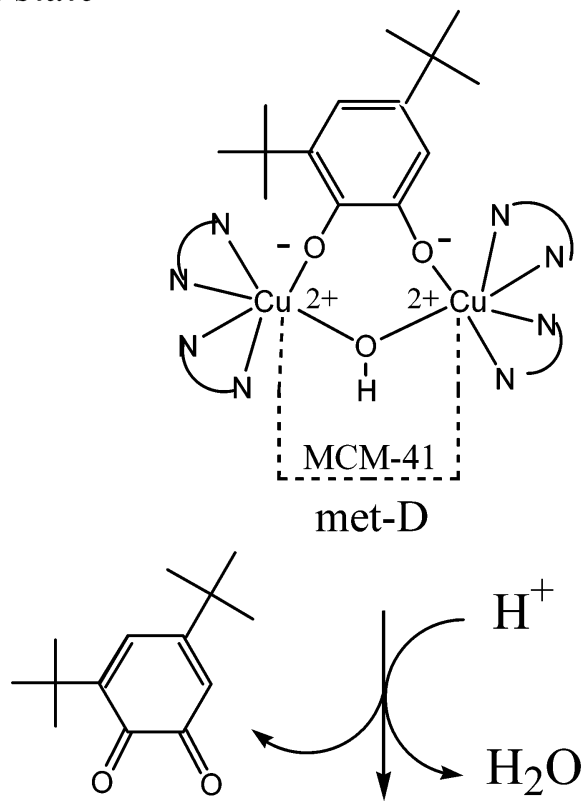

met state
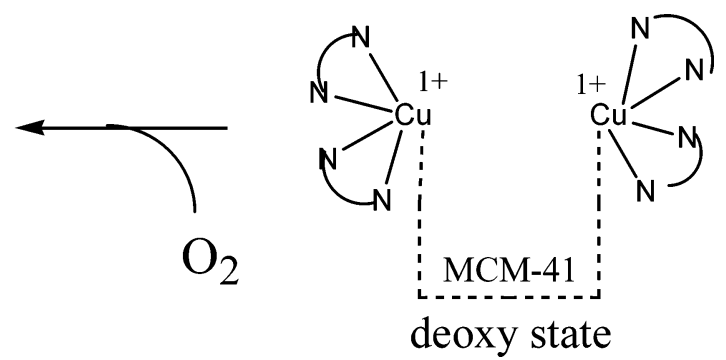

during the conversion of $\mathrm{Cu}(\mathrm{II})$ centers in the catalytic reaction. We first studied the oxidation reaction in the presence of $\mathrm{H}_{2} \mathrm{O}_{2}$. It was reported previously that the $\mu$-oxo dinuclear $\mathrm{Cu}(\mathrm{II})$ complex can be converted into $\mu$-peroxo dinuclear $\mathrm{Cu}$ (II) complex using hydrogen peroxide as an oxidant at $-35^{\circ} \mathrm{C} .{ }^{37,40}$ We therefore added $5.8 \mathrm{mmol}$ of $\mathrm{H}_{2} \mathrm{O}_{2}$ to $50 \mathrm{mg}$ of $\mathrm{HPC}-\mathrm{M}_{\mathrm{T}}$ to test this simple oxidation using our synthetic enzyme. The EPR spectrum taken at $80 \mathrm{~K}$ is displayed in Figure 6a. The spectrum shows a decrease of $\Delta M_{s}= \pm 2$ intensity at $1600 \mathrm{G}$ and $\Delta M_{s}= \pm 1$ around $2800 \mathrm{G}$ that may be attributed to part of the hydroxo bridge dinuclear $\mathrm{Cu}(\mathrm{II})$ complexes converting into $\mu$-peroxo dinuclear $\mathrm{Cu}$ (II) complexes (shorter $\mathrm{Cu} \cdots \mathrm{Cu}$ distance) which are EPR-silent as a result of strong coupling between the two copper centers. 


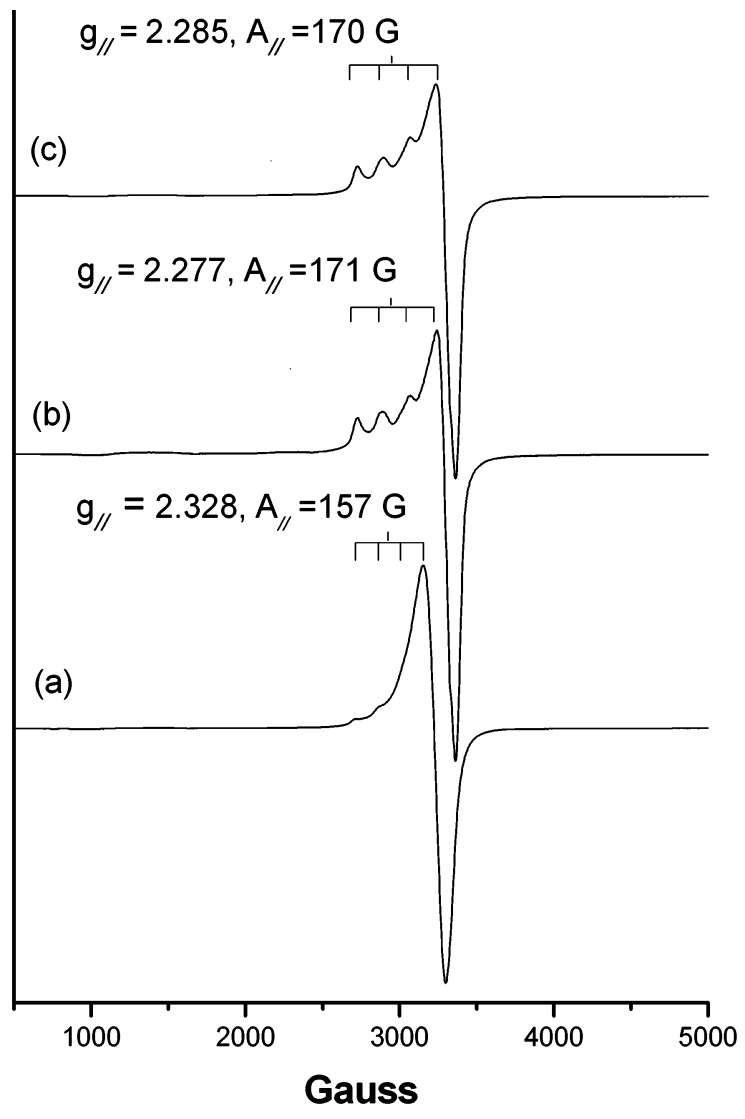

Figure 5. EPR spectra of the following samples at $80 \mathrm{~K}$ : (a) HPC$\mathrm{Y}$, (b) HPC-uncalcined- $\mathrm{M}_{\mathrm{T}}$, and (c) HPC-uncalcined- $\mathrm{M}_{\mathrm{P}}$ solids.

We then further studied the catalytic oxidation of DTBC with dioxygen in the presence of triethylamine by monitoring the time evolution of EPR spectral intensity in the course of reaction. After $1 \mathrm{~h}$ of reaction time, the $\mathrm{HPC}-\mathrm{M}_{\mathrm{T}}$ solids were washed with pure methanol and dried in a vacuum. The solids spectrum of $\mathrm{HPC}-\mathrm{M}_{\mathrm{T}}$ sample (Figure $6 \mathrm{~b}$ ) gives a weak mononuclear $\mathrm{Cu}(\mathrm{II})$ signal at $3150 \mathrm{G}$. However, the intensity of $\Delta M_{s}= \pm 2$ at $1600 \mathrm{G}$ and $\Delta M_{s}= \pm 1$ at $2800 \mathrm{G}$ transition remain relatively strong, which indicates there is still a large amount of dinuclear $\mathrm{Cu}$ (II) met form remaining in $\mathrm{HPC}-\mathrm{M}_{\mathrm{T}}$ solids. Thus, we have demonstrated that the nanochannels of MCM-41 can indeed provide stability and prevent much of the dinuclear $\mathrm{Cu}$ (II) complexes from dissociating in the catalytic cycle.

The solution phase of the reaction mixture in DTBC oxidation catalyzed by $\mathrm{HPC}-\mathrm{M}_{\mathrm{T}}$ in the presence of triethylamine was also followed by EPR. After $1 \mathrm{~h}$ of reaction time, the HPC$\mathrm{M}_{\mathrm{T}}$ solids were separated by means of a syringe filter. The EPR spectra of methanol-frozen solutions taken at $80 \mathrm{~K}$ are displayed in Figure $6 c, c^{\prime}$ (Figure $6 c^{\prime}$ is the expanded scale of Figure $6 c$ in the range of $3225-3525 \mathrm{G})$. The absence of the signal at $1600 \mathrm{G}$ indicates that dinuclear cupric complexes are stable inside the nanochannels of $\mathrm{Al}-\mathrm{MCM}-41$. This is consistent with the elemental analysis which gives $7 \%$ of cupric ions leaching into the methanol solution from the $\mathrm{HPC}-\mathrm{M}_{\mathrm{T}}$ solids. They are present mostly as mononuclear cupric complexes on the external surfaces of $\mathrm{HPC}-\mathrm{M}_{\mathrm{T}}$ formed in the catalytic cycle, which likely come from the irreversible dissociation of the dinuclear cupric complexes.

We further observed a parallel component at $g_{\|}=2.248$ with $A_{\|}=186 \mathrm{G}$ in the leached mononuclear cupric complexes (Figure 6c). Previously, $g_{\|}=2.239$ and $A_{\|}=187 \mathrm{G}$ have been assigned to a square planar tetraammonia complex $[\mathrm{Cu}-$ $\left.\left(\mathrm{NH}_{3}\right)_{4}\right]^{2+}$, and $g_{\|}=2.240$ and $A_{\|}=170 \mathrm{G}$ are for nitrogen

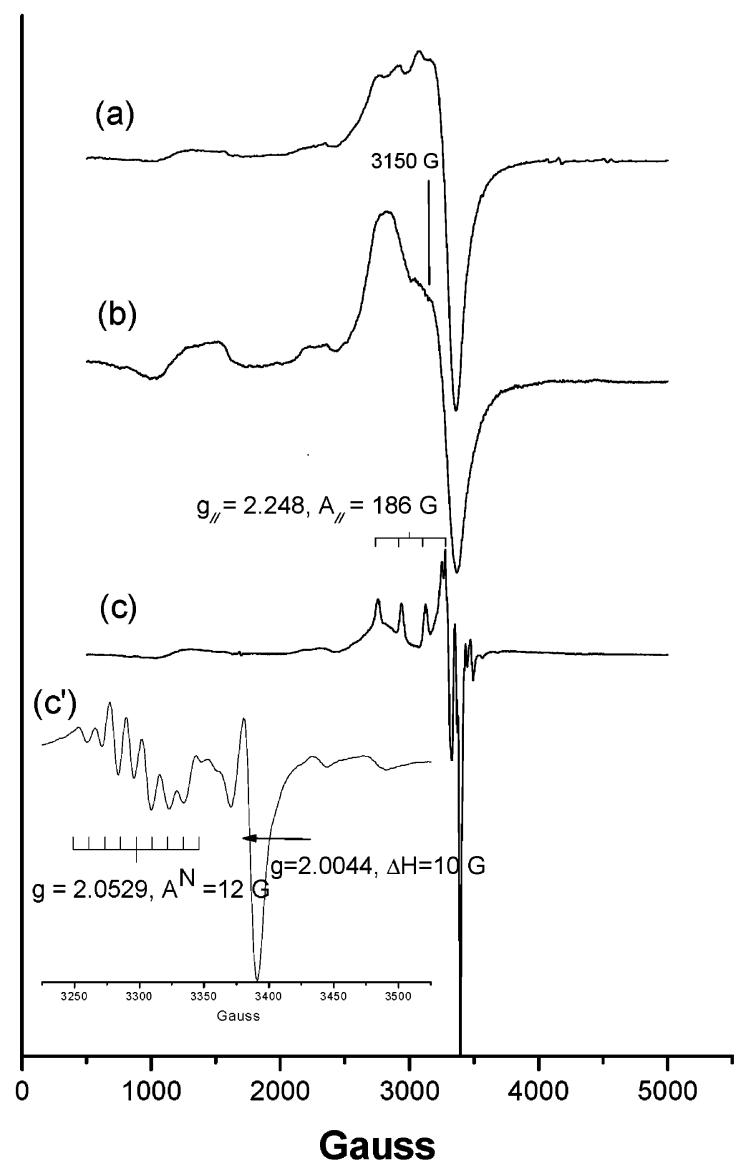

Figure 6. EPR spectra of the following samples at $80 \mathrm{~K}$ : (a) HPC$\mathrm{M}_{\mathrm{T}}$ solids reacted with $\mathrm{H}_{2} \mathrm{O}_{2}$, (b) HPC $-\mathrm{M}_{\mathrm{T}}$ solids after catalytic DTBC oxidation, and (c) solution phase of the reaction mixture after addition of $30 \mu \mathrm{L}$ of triethylamine in the catalytic reaction. The expanded scale (in the range of $3225-3525 \mathrm{G}$ ) shown in (c') displays detailed spectral features.

coordinated to $\mathrm{Cu}$ (II) ion in a distorted octahedral geometry. ${ }^{39,41}$ Interestingly, we also observed that nine ${ }^{14} \mathrm{~N}(I=1)$ super hyperfine structures appeared in the $g_{\perp}=2.0529$ region with $A^{\mathrm{N}}=12 \mathrm{G}$. From the measured EPR parameters we may infer that the $\mathrm{Cu}$ (II) complexes leached into the reaction mixture may form a six-coordinated configuration. Four nitrogen atoms are provided by the original two phenanthroline ligands, and the extra coordination (in axial geometry) may come from the nitrogen atoms of the triethylamine solvent. We further observed that a signal appeared at $g=2.0044(3380 \mathrm{G})$ in Figure $6 \mathrm{c}^{\prime}$, which is attributed to the formation of a stable $o$-semiquinone radical. ${ }^{19}$ The presence of the $o$-semiquinone radical in the catalytic mixture has also been observed in the homogeneous and heterogeneous catalysis of DTBC oxidation.

Since we observed that a large quantity of dinuclear cupric complexes remained after the catalytic cycle and only a small amount of dinuclear cupric complexes was leached into the solution phase, we may conclude that the HPC $-\mathrm{M}_{\mathrm{T}}$ solids are effective artificial enzymes (heterogeneous catalysts) for the oxidation of DTBC to DTBQ.

(d) EXAFS Spectra. Figure 7 compares the EXAFS spectra (not corrected for phase shift) of pure HPC, HPC- $\mathrm{M}_{\mathrm{T}}$, and $\mathrm{HPC}-\mathrm{M}_{\mathrm{T}}$ after reaction with DTBC. The spectra correspond to various scattering or neighboring atoms situated at different distances from the central absorbing copper atom. The assignment of the nitrogen/oxygen (N/O) and copper $(\mathrm{Cu} 1$ and $\mathrm{Cu} 2)$ peaks has been described in our previous paper. ${ }^{28}$ We shall discuss the origin of the $\mathrm{Cu} 1, \mathrm{Cu} 2$, and $\mathrm{Cu} 3$ peaks below. 


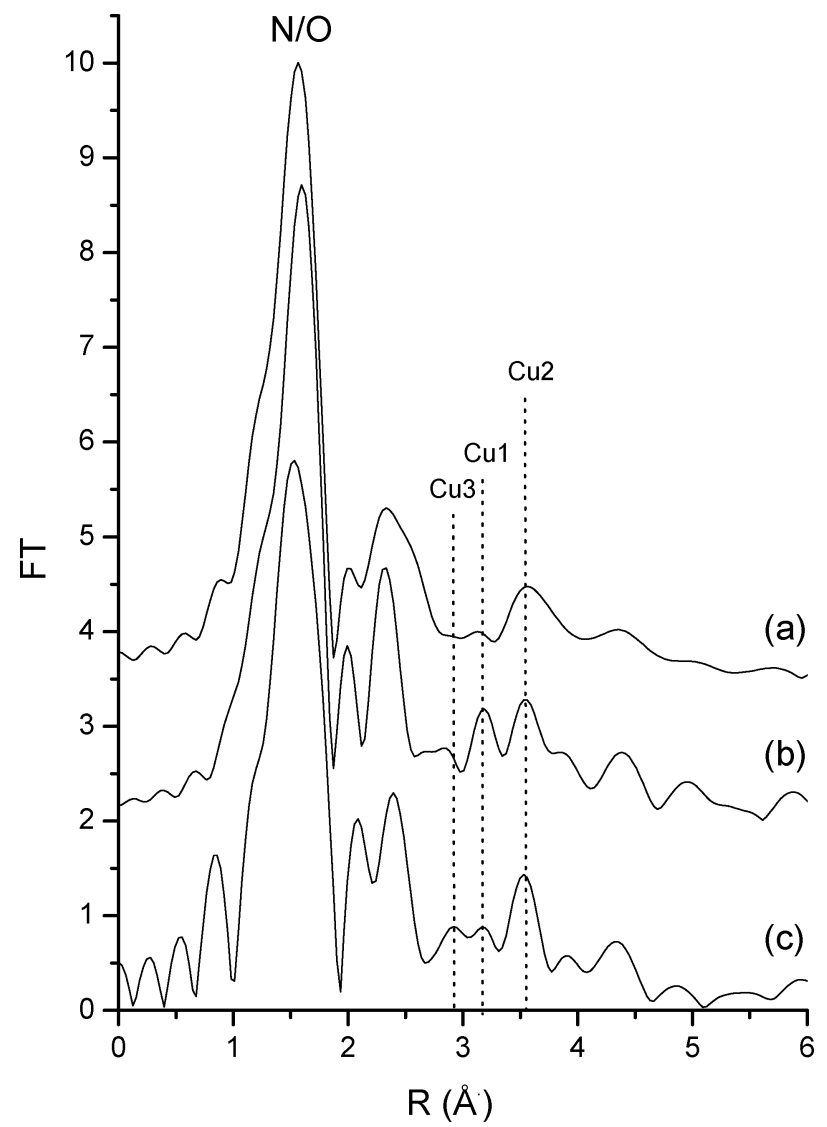

Figure 7. $\mathrm{Cu}$ K-edge EXAFS spectra (without phase shift correction) of (a) pure HPC crystalline solids, (b) $\mathrm{HPC}-\mathrm{M}_{\mathrm{T}}$, and (c) $\mathrm{HPC}-\mathrm{M}_{\mathrm{T}}$ after reaction with methanol solution of DTBC for $20 \mathrm{~min}$.

All EXAFS spectra gave the $\mathrm{Cu} 1$ and $\mathrm{Cu} 2$ peaks. The $\mathrm{Cu} 1$ peak belongs to the pristine HPC complex with a bond distance of $3.51 \AA$, while $\mathrm{Cu} 2$ originates from the decomposition or dissociation of this HPC complex as the sample was subjected to X-ray irradiation during the data collection process. Accordingly, the intensity of the $\mathrm{Cu} 2$ peak is much higher than that for $\mathrm{Cu} 1$ in pure $\mathrm{HPC}$ (Figure 7a) as compared to $\mathrm{HPC}-\mathrm{M}_{\mathrm{T}}$ (Figure $7 b$ ) since there is no support to protect the HPC complex. Therefore, the confined space of the channel system of mesoporous MCM-41 can stabilize the HPC complex and prevent excessive dissociation of its structure.

We also recorded the EXAFS spectrum of $\mathrm{HPC}-\mathrm{M}_{\mathrm{T}}$ after reaction with a methanol solution of DTBC for $20 \mathrm{~min}$ (Figure 7c). In this case, the solid sample was separated by filtration, then washed twice with methanol, and dried under vacuum. It is interesting to observe that this sample showed a new $\mathrm{Cu} 3$ peak at a bond distance of about $3.30 \AA$. At the same time, there is a concomitant decrease in the intensity of its $\mathrm{Cu} 1$ peak when compared to $\mathrm{HPC}-\mathrm{M}_{\mathrm{T}}$ before the reaction. This phenomenon is largely due to the structural transformation of HPC from the met state $(\mathrm{Cu} 1$ peak) into the met-D state $(\mathrm{Cu} 3$ peak) after the coordination of DTBC to the dicupric center of HPC as shown in Scheme 1. The $\mathrm{Cu} \cdots \mathrm{Cu}$ distance decreases by about $0.21 \AA$ during the structural transformation from $\mathrm{Cu} 1$ to $\mathrm{Cu} 3$. Furthermore, the $\mathrm{Cu}-\mathrm{Cu}$ distance of $\mathrm{Cu} 3$ peak is close to 3.25 $\AA$ reported for pure $o$-catecholate-bridged dicopper complex by Karlin et al. ${ }^{42}$ Our EXAFS results thus demonstrated clearly that the $\mathrm{Cu} \cdots \mathrm{Cu}$ distance of HPC complex in $\mathrm{HPC}-\mathrm{M}_{\mathrm{T}}$ is compatible to the $\mathrm{O} \cdots \mathrm{O}$ distance of the two hydroxyl groups of DTBC, and this made a simultaneous coordination of the diol group to the dicupric center possible. The resultant complex then allows the transfer of two electrons from DTBC to the dicupric center leading to the production of DTBQ and two monocuprous centers held close to each other by the confined space of the MCM-41 channels. The two monocuprous centers can take up an oxygen molecule and regenerate the dicupric center again for the catalytic cycle to proceed as shown in Scheme 1.

4. Catalytic Activities. As we mentioned, the role of catecholase in biological systems is to oxidize catechols to the corresponding quinones. Thus, we used 3,5-di-tert-butylcatechol (DTBC) as a convenient model substrate, to study the biomimetic efficacy of the dicupric complexes dispersed in mesoporous silca. ${ }^{9-19,29}$ Previously, Kida et al. reported a study of $\mathrm{Cu}(\mathrm{II})$ systems in which they showed the efficacy of dinuclear $\mathrm{Cu}(\mathrm{II})$ complexes in catalyzing the oxidation reaction while mononuclear complexes are either ineffective or inactive. ${ }^{43,44}$ The high activity of dinuclear $\mathrm{Cu}$ (II) complexes was explained in terms of the close proximity of two metal centers that could facilitate the binding of the two oxygen atoms of the catechol during the electron-transfer process. ${ }^{43}$ The TON (turnover number) and the selectivity of DTBQ in the presence of $\mathrm{HPC}-\mathrm{M}_{\mathrm{P}}, \mathrm{HPC}-\mathrm{M}_{\mathrm{T}}$, and $\mathrm{HPC}-\mathrm{Y}$ samples are given in Table 2.

We note the following: (a) The reaction activity depends on the amount of base used. The more base was added, the higher reaction activity that was observed. The added triethylamine seems to promote the formation of the initial dicopper-catechol complex by proton abstraction of DTBC. ${ }^{19}$ (b) In the absence of base, all samples have a low TON $\left(35 \mathrm{~h}^{-1}\right.$ for HPC- $\mathrm{M}_{\mathrm{T}}$ and $15 \mathrm{~h}^{-1}$ for $\mathrm{HPC}-\mathrm{Y}$ sample). As the reaction time increases, the DTBC conversion is increased slightly but the selectivity of DTBQ is decreased (data not shown). (c) With the addition of $30 \mu \mathrm{L}$ of triethylamine, the TON is increased in HPC $-\mathrm{M}_{\mathrm{T}}$ samples $\left(137 \mathrm{~h}^{-1}\right)$, which is greater than those in $\mathrm{HPC}-\mathrm{M}_{\mathrm{P}}(117$ $\left.\mathrm{h}^{-1}\right)$ and HPC $-\mathrm{Y}\left(57 \mathrm{~h}^{-1}\right)$ samples. The higher TON of HPC$\mathrm{M}_{\mathrm{T}}$ in comparison with $\mathrm{HPC}-\mathrm{M}_{\mathrm{P}}$ may come from the existence of many defects in the structure of $\mathrm{M}_{\mathrm{T}}$, which may improve the interchannel diffusion or porosity of the catalyst. ${ }^{45}$ The low TON and DTBQ selectivity of HPC-Y samples may come from the presence of a large amount of mononuclear cupric complexes which were formed in the irreversible dissociation of the dinuclear cupric complex on the external surfaces of HPC-Y. The mononuclear cupric complexes could catalyze the oxidation of DTBC to other side products. (d) The selectivity of DTBQ in $\mathrm{HPC}-\mathrm{M}_{\mathrm{P}}$ and the selectivity of DTBQ in $\mathrm{HPC}-\mathrm{M}_{\mathrm{T}}$ are both $100 \%$, which are higher than that in HPC $-\mathrm{Y}(69 \%)$ after $1 \mathrm{~h}$ of reaction time. The highest selectivity comes from the HPC$\mathrm{M}_{\mathrm{P}}$ and $\mathrm{HPC}-\mathrm{M}_{\mathrm{T}}$ samples, which gave $100 \%$ DTBQ selectivity when $30 \mu \mathrm{L}$ of triethylamine was added. Thus, in the presence of $\mathrm{HPC}-\mathrm{M}_{\mathrm{P}}$ or $\mathrm{HPC}-\mathrm{M}_{\mathrm{T}}$ catalyst, DTBC is observed almost fully reacted and DTBQ is the sole oxidation product. (e) The selectivity of HPC-Y sample is relatively lower than that of the other samples that may arise from the overoxidation of DTBC by the mononuclear cupric complex which was formed by irreversible dissociation of the dinuclear cupric complex on the external surfaces of HPC-Y.

5. Reaction Mechanism. The catalytic cycle of the oxidation of DTBC to DTBQ involves four-electron reduction of dioxygen to water. Based on the spectroscopic studies, a possible catalytic pathway is depicted in Scheme 1. At first, the added base abstracts the acidic protons from DTBC. The negatively charged DTBC will coordinate to the met form of dinuclear $\mathrm{Cu}(\mathrm{II})$ complex and form the dicopper-catechol complex (met-D) as an intermediate. The first DTBQ is formed via the two-electron redox reaction. $\mathrm{The} \mathrm{Cu}(\mathrm{II})$ ions are reduced to the deoxy state of $\mathrm{Cu}(\mathrm{I})$ ions by removing the hydroxo bridge in the uptake of 
a proton and release of a water molecule. The dioxygen can bind to the dinuclear $\mathrm{Cu}(\mathrm{I})$ complex, forming an oxy state of dinuclear $\mathrm{Cu}$ (II) complex. The function of dioxygen in the catalytic reaction is a thermodynamic driving process, in which any nascent $\mathrm{Cu}(\mathrm{I})$ species are reoxidized back to the active $\mathrm{Cu}$ (II) species and begin another catalytic cycle.

The oxidation of DTBC can also be carried out by the oxy state $\left[\mathrm{Cu}^{\mathrm{II}}-\mathrm{O}_{2}{ }^{2-}-\mathrm{Cu}^{\mathrm{II}}\right]$. The oxy-D intermediate can further transfer two electrons from DTBC to the peroxide followed by the protonation of peroxide group and the cleavage of $\mathrm{O}-\mathrm{O}$ bond. The rate of breaking of the $\mathrm{O}-\mathrm{O}$ bond in the oxy-D dinuclear cupric complex is much faster than that in the mononuclear cupric system because of the two-electron-transfer process involved. ${ }^{2}$ The difference in activation energy for the one-electron versus two-electron reductive cleavage would lead to a $10^{7}$-fold increase in the peroxide reduction rate because of the larger thermodynamic driving force in the two-electrontransfer process. In other words, the dinuclear copper in biological systems provides a fast strategy for the reductive cleavage of $\mathrm{O}-\mathrm{O}$ bonds. Thus, the type III copper enzymes are more effective in dioxygen activation in biological catalysis.

\section{Conclusions}

We have demonstrated that the hydroxo-bridged dinuclear cupric complexes can be incorporated into the nanochannels of Al-MCM-41 via an ion-exchange method. The encapsulated dinuclear cupric complexes were applied to carry out the catalytic oxidation of DTBC to DTBQ in mimicking COs. The nanochannels of $\mathrm{Al}-\mathrm{MCM}-41$ mesoporous solids provide confined spaces and surface charge to encapsulate and stabilize HPC complexes in carrying out the catalytic reaction where the HPC undergoes reversible transformation between bridging and nonbridging states. Thus, we may envision the framework of MCM-41 to be equivalent to the backbone of the protein skeleton of enzymes in which the two $\mathrm{Cu}$ (II) nuclei of HPC are fixed in position with the proper distance and configuration for catalytic activities.

The EXAFS studies showed the two $\mathrm{Cu}$ (II) centers in $\mathrm{Al}-$ MCM-41 channels are fixed in close proximity of $3.51 \AA$. The $\mathrm{UV}-$ vis and EPR spectra showed that the majority of copper complexes in $\mathrm{M}_{\mathrm{P}}$ and $\mathrm{M}_{\mathrm{T}}$ are in the dinuclear form and retain their integrity even after cycles of the catalytic oxidation of DTBC to DTBQ, where two proximate cupric sites with a hydroxo bridge can be restored easily in the catalytic cycle as shown in Scheme 1. The spectra of EXAFS and UV-vis also showed that the two hydroxyl groups of DTBC coordinated cooperatively during the electron-transfer process. In the reaction with $\mathrm{H}_{2} \mathrm{O}_{2}$, we observed a conversion of hydroxo-bridged dinuclear $\mathrm{Cu}$ (II) complexes into $\mu$-peroxo dinuclear $\mathrm{Cu}$ (II) complexes and a shortening of $\mathrm{Cu} \cdots \mathrm{Cu}$ distance. We also observed a semiquinone radical derived from DTBC as a reaction intermediate in the EPR study. Previously, we showed that dinuclear cupric complexes could catalyze effectively the oxidation of benzyl alcohol by tert-butylhydroperoxide. Here we further demonstrate both $\mathrm{HPC}-\mathrm{M}_{\mathrm{T}}$ and $\mathrm{HPC}-\mathrm{M}_{\mathrm{P}}$ provide effective catalytic oxidation of DTBC to DTBQ: high DTBC activity and DTBQ selectivity. On the other hand, zeolite Y with smaller pore size is ineffective in this catalytic oxidation, which is attributed to only mononuclear cupric complexes being embedded in the microporous zeolite. The mononuclear cupric complexes were less DTBC active and had lower DTBQ selectivity than the dinuclear complexes. Thus, HPC or other catalytic centers encapsulated in mesoporous materials could be utilized as a viable target system for a broad range of catalytic activities to mimic naturally occurring enzymes; the synthetic enzymes may become feasible routes to mimic nature.

Acknowledgment. This work was supported by a grant from the Ministry of Education through the Academy Excellent program. T.-S.L. acknowledges partial support by a grant from NSF (INT0115082) and a PRF grant administered by the American Chemical Society (36970).

\section{Abbreviations and Notations}

$\mathrm{Al}-\mathrm{MCM}-41$ = aluminum-containing MCM-41

$\mathrm{DTBC}=3,5$-di-tert-butylcatechol

DTBQ $=3,5$-di-tert-butylquinone

phen $=$ phenanthroline ligand

$\mathrm{HPC}=\left[(\text { phen })_{2} \mathrm{Cu}-\mathrm{OH}-\mathrm{Cu}(\text { phen })_{2}\right]\left(\mathrm{ClO}_{4}\right)_{3}$ complex

$\mathrm{M}_{\mathrm{T}}=\mathrm{Al}-\mathrm{MCM}-41$ in tubular form

$\mathrm{M}_{\mathrm{P}}=\mathrm{Al}-\mathrm{MCM}-41$ in particulate form

$\mathrm{HPC}-\mathrm{M}_{\mathrm{T}}=\mathrm{HPC}$ in tubular Al-MCM-41 by ion-exchange method

$\mathrm{HPC}-\mathrm{M}_{\mathrm{P}}=\mathrm{HPC}$ in particulate $\mathrm{Al}-\mathrm{MCM}-41$ by ionexchange method

$\mathrm{HPC} / \mathrm{M}_{\mathrm{PS}}=\mathrm{HPC}$ in pure silica form of particulate MCM41 by impregnation method

\section{References and Notes}

(1) Bioinorganic Chemistry of Copper; Karlin, K. D., Tyeklar, Z., Eds.; Chapman \& Hall: New York, 1993.

(2) Solomon, E. I.; Chen, P.; Metz, M.; Lee, S. K.; Palmer, A. E. Angew. Chem., Int. Ed. 2001, 40, 4570.

(3) Magnus, K. A.; Ton-That, H.; Carpenter, J. E. Chem. Rev. 1994 94,727

(4) Trémolières, J. B.; Bieth, J. B. Phytochemistry 1984, 23, 501.

(5) Klabunde, T.; Eicken, C.; Sacchettini, J. C.; Krebs, B. Nat. Struct. Biol. 1998, 5, 1084 183.

(6) Gerdemann, C.; Eicken, C.; Krebs, B. Acc. Chem. Res. 2002, 35,

(7) Solomon, E. I.; Sundaram, U. M.; Machonkin, T. E. Chem. Rev. 1996, 96, 2563.

(8) Than, R.; Feldmann, A. A.; Krebs, B. Coord. Chem. Rev. 1999, 182, 211.

(9) Torelli, S.; Belle, C.; Gautier-Luneau, I.; Pierre, J. L.; Saint-Aman, E.; Latour, J. M.; Le Pape, L.; Luneau, D. Inorg. Chem. 2000, 39, 3526.

(10) Belle, C.; Beguin, C.; Gautier-Luneau, I.; Hamman, S.; Philouze, C.; Pierre, J. L.; Thomas, F.; Torelli, S. Inorg. Chem. 2002, 41, 479.

(11) Torelli, S.; Belle, C.; Hamman, S.; Pierre, J. L. Inorg. Chem. 2002 41, 3983.

(12) Reim, J.; Krebs, B. J. Chem. Soc., Dalton Trans. 1997, 3793.

(13) Mukherjee, J.; Mukherji, R. Inorg. Chim. Acta 2002, 337, 429.

(14) Zippel, F.; Ahlers, F.; Werner, R.; Haase, W.; Nolting, H.-F.; Krebs, B. Inorg. Chem. 1996, 35, 3409.

(15) Neves, A.; Rossi, L. M.; Bortoluzzi, A. J.; Szpoganicz, B.; Wiezbicki, C.; Schwingel, E.; Haase, W.; Ostrovsky, S. Inorg. Chem. 2002, $41,1788$.

(16) Fernandes, C.; Neves, A.; Bortoluzzi, A. J.; Mangrich, A. S.; Rentschler, E.; Szpoganicz, B.; Schwingel, E. Inorg. Chim. Acta 2001, 320, 12 .

(17) Gentschev, P.; Moller, N.; Krebs, B. Inorg. Chim. Acta 2000, 300, 442.

(18) Rockcliffe, D. A.; Martell, A. E. J. Mol. Catal., A 1996, 106, 211

(19) Louloudi, M.; Mitopoulou, K.; Evaggelou, E.; Deligiannakis, Y.; Hadjiliadis, N. J. Mol. Catal. A Chem. 2003, 198, 231.

(20) Robert, R.; Patnasamy, P. J. Mol. Catal. A Chem. 1995, 100, 93. 99.

(21) Ganesan, R.; Viswanathan, B. J. Mol. Catal. A Chem. 2002, 181,

(22) Viana Rosa, I. L.; Manso, C. M. C. P.; Serra, O. A.; Iamamoto, Y J. Mol. Catal. A Chem. 2000, 160, 199.

(23) Seelan, S.; Sinha, A. K. Appl. Catal. A: Gen. 2003, 238, 201.

(24) Karandikar, P.; Dhanya, K. C.; Deshpande, S.; Chandwadkar, A. J.; Sivasanker, S.; Agashe, M. Catal. Commun. 2004, 5, 69.

(25) Lin, H. P.; Mou, C. Y. Acc. Chem. Res. 2002, 35, 927.

(26) Lin, H. P.; Mou, C. Y. Science 1996, 273, 765

(27) (a) Lee, C. H.; Lin, T. S.; Mou, C. Y. Phys. Chem. Chem. Phys. 2002, 4, 3106. (b) Lee, C. H.; Lin, T. S.; Mou, C. Y. J. Phys. Chem. B 2003, 107, 2543. 
(28) Wong, S. T.; Lee, C. H.; Lin, T. S.; Mou, C. Y. J. Catal. 2004, 228,1

(29) (a) Monzani, E.; Quinti, L.; Perotti, A.; Casella, L.; Gullotti, M.; Randaccio, L.; Geremia, S.; Nardin, G.; Faleschini, P.; Tabbi, G. Inorg. Chem. 1998, 37, 553. (b) Malachowski, M. R.; Huynh, H. B.; Tomlinson, L. J.; Davidson, M. G.; Kelly, R. S.; Furbee, J. W. J. Chem. Soc., Dalton Trans. 1995, 31. (c) Torelli, S.; Belle, C.; Gautier-Luneau, I.; Pierre, J. L.; Saint-Aman, E.; Latour, J. M.; Le Pape, L.; Luneau, D. Inorg. Chem. 2001, 39, 3526. (d) Srinivas, B.; Arulsamy, N.; Zacharias, P. S. Polyhedron 1991, 10, 731. (e) Gupta, M.; Mathur, P.; Butcher, R. J. Inorg. Chem. 2001, 40, 878. (f) Manzur, J.; Garcia, A. M.; Rivas, V.; Atria, A. M.; Valenzuela, J.; Spodine, E. Polyhedron 1997, 16, 2299.

(30) Haddad, M. S.; Wilson, S. R.; Hodgson, D. J.; Hendrickson, D. N. J. Am. Chem. Soc. 1981, 103, 384.

(31) Lin, H. P.; Mou, C. Y. J. Cluster Sci. 1999, 10, 271.

(32) Brown, J. M.; Powers, L.; Kincaid, B.; Larrabee, J. A.; Spiro, T. G. J. Am. Chem. Soc. 1980, 102, 4210 .

(33) Morizzi, J.; Hobday, M.; Rix, C. Inorg. Chim. Acta 2001, 320, 67. 210 .
(35) Gao, J.; Zhong, S. H. J. Mol. Catal. A Chem. 2000, 164, 1.

(36) Zheng, S.; Gao, L.; Guo, J. J. Solid State Chem. 2000, 152, 447.

(37) Kitajima, N.; Koda, T.; Moro-Oka, Y. Chem. Lett. 1988, 347.

(38) Abragam, A.; Bleaney. B. Electron Paramagnetic Resonance of Transition Ions; Clarendon Press: Oxford, UK, 1970; Chapter 7.

(39) Murali, A.; Chang, Z.; Ranjit, K. T.; Krishna, R. M.; Kurshev, V.; Kevan, L. J. Phys. Chem. B 2002, 106, 6913.

(40) Kitajima, N.; Koda, T.; Hashimoto, S.; Kitagawa, T.; Moro-oka, Y. J. Chem. Soc., Chem. Commun. 1988, 151.

(41) Xu, J.; Yu, J. S.; Lee, S. J.; Kim, B. Y.; Kevan, L. J. Phys. Chem. B 2000, 104, 1307 .

(42) Karlin, K. D.; Gultneh, Y.; Nicholson, T.; Zubieta, J. Inorg. Chem. 1985, 24, 3725

(43) Oishi, N.; Nishida, Y.; Ida, K.; Kida, S. Bull. Chem. Soc. Jpn. 1980, $53,2847$.

(44) Kida, S.; Okawa, H.; Nishioda, Y. In Copper Coordination Chemistry: Biochemical and Inorganic Perspectives; Karlin, K. D., Zubieta, J., Eds.; Adenine Press: Guiderland, NY, 1983; p 425.

(45) Lin, H. P.; Wong, S. T.; Mou, C. Y.; Tang, C. Y. J. Phys. Chem. B 2000, 104, 8967 . 